\title{
A cross sectional observational study to evaluate the maternal and fetal outcome in postdated pregnancies
}

\author{
Ritika Narayan*, Sheela S. R.
}

Department of Obstetrics and Gynecology, Sir Devraj Urs Medical College, Kolar, Karnataka, India

Received: 19 February 2020

Revised: 16 November 2020

Accepted: 17 November 2020

\author{
*Correspondence: \\ Dr. Ritika Narayan, \\ E-mail: drnarayan05@gmail.com
}

Copyright: ( $)$ the author(s), publisher and licensee Medip Academy. This is an open-access article distributed under the terms of the Creative Commons Attribution Non-Commercial License, which permits unrestricted non-commercial use, distribution, and reproduction in any medium, provided the original work is properly cited.

\begin{abstract}
Background: Post-dated pregnancy is when the gestation is more than 40 weeks or 280 days. They last longer than the estimated date of delivery. Postdated pregnancies are associated with increased perinatal and maternal complications. These risks are greater than it was originally thought. Risks have been underestimated in the past leading to increasing number of complicated postdated pregnancies which appears to be otherwise low risk. The maternal risks are very often underappreciated resulting in increased maternal morbidity.

Methods: This cross sectional observational study was done to evaluate maternal and fetal complications associated with Postdated pregnancies was carried out in the department of obstetrics and gynecology in a tertiary care centre, Sir Devraj Urs Medical College and RL Jalappa Hospital, Kolar between July 2018 and July 2019, fulfilling all the inclusion and exclusion criteria.

Results: 50 out of 100 patients had full term normal deliveries where as $45 \%$ patients required cesarean section. Most common indication for cesarean section was meconium stained liquor with fetal distress (25\%). $42 \%$ of the babies born needed NICU admission. Most common maternal complication seen was Postpartum Hemorrhage.

Conclusions: The present study we conclude that postdated pregnancy was associated with significant risk of perinatal complications such as fetal distress, meconium aspiration syndrome and IUGR. There was increased risk of obstetric complications as well like atonic PPH, oligohydramnios, obstructed labor.
\end{abstract}

Keywords: Cesarean section, Fetal outcome, Maternal morbidity, NICU admissions, Postdated pregnancy

\section{INTRODUCTION}

Post-dated pregnancy is when the gestation is more than 40 weeks or 280 days. They last longer than the estimated date of delivery also known as the due date in layman's terms. Pregnant women who have passed their estimated date of delivery but who have not reached 42 weeks of gestation yet (those between 40 and 42 completed weeks of gestation) remain an important group for whom there is ongoing research regarding antenatal fetal surveillance and indications for induction of labour. ${ }^{1}$ The prevalence varies worldwide but is estimated to be $5-10 \%$. The reported frequency of post term pregnancy is $3-12 \%$.
Assuming that the incidence of postdate pregnancy may be slightly higher than that of post term is reasonable. ${ }^{2}$

Although a 2004 Practice Bulletin from the American College of Obstetricians and Gynecologists recommends avoiding the term "postdates" owing to its being poorly defined, this term continues to be used as a common reason for induction of labor for pregnancies that continue after 41 completed weeks of gestation. ${ }^{3}$

It is associated with an increased risk of perinatal mortality and morbidity together with a higher risk of maternal obstetrical complications. It has been reported 
that in a pregnancy that has crossed its expected date of delivery there is an increased risk of oligohydramnios, meconium stained amniotic fluid, macrosomia fetal post maturity syndrome, and caesarean delivery, all of which jeopardize the baby and the mother. ${ }^{4}$

Prolonged pregnancy is regarded as a high risk condition because perinatal morbidity and mortality is known to rise. The interest in postdatism is recent and the management is controversial, more so with the advent of sonography providing information about placental ageing and amount of amniotic fluid. ${ }^{4}$

The most common cause of prolonged pregnancies is inaccurate dating. ${ }^{5,6}$ The use of standard clinical criteria to determine the estimated date of delivery tends to overestimate the gestational age and consequently increases the incidence of postdated pregnancies. Common risk factors for postdated pregnancies include primiparity, previous prolonged pregnancy, male fetus, obesity, hormonal factors and genetic predisposition. ${ }^{7-10}$ Altered levels of circulating hormones that are thought to play a role in the causation of spontaneous labor may also play a role in the causation of prolonged pregnancy. Abnormal fetal HPA and adrenal hypoplasia as in anencephaly results in deficiency of dehydroepiandrosterone which leads to reduced fetal cortisol response and hence delayed onset of labor. Placental sulfatase deficiency, a rare $\mathrm{X}$ linked disorder can prevent spontaneous labor due to defect in the placental sulfatase activity and the resulting decreased estriol levels.

The combination of continued fetal growth and arrested placental growth may lead to situation of decreasing placental reserve, compromised fetal circulation and eventually fetal distress. According to an electron microscopy study of placental changes in prolonged pregnancy suggests uteroplacental ischemia and not ageing may be more important in the genesis of post maturity. ${ }^{11}$

The perinatal mortality rate at 42 weeks is twice as high as at term, increases to 4 folds at 43 weeks and 5-7 folds at 44 weeks. $^{12}$ It is believed that uteroplacental insufficiency, meconium aspiration and intrauterine infection are the underlying cause of the increased perinatal mortality in such cases. ${ }^{13}$ Fetal morbidity also increases beyond 41 weeks of gestation. This includes passage of meconium, macrosomia, neonatal acidemia and dysmaturity. Birthweight in excess of $4000 \mathrm{~g}$ are threefold to sevenfold more common in postdated pregnancies with an overall incidence of $25 \%$ at 42 weeks. ${ }^{14}$

As the pregnancy progresses towards its culmination a series of changes occur in the amniotic fluid, placenta and fetus. Amniotic fluid gradually decreases and it has been observed that after 42 weeks there is $33 \%$ decrease in amniotic fluid volume. Pregnancy beyond 40 weeks needs frequent Amniotic fluid index monitoring. ${ }^{15}$ Decrease in renal blood flow is associated with postdatism which is the cause for this oligohydramnios. It also becomes milky and cloudy because of presence of abundant flakes of vernix caseosa. It may also become meconium stained as a result of intrauterine hypoxia. Placental changes can be seen on USG - the indentation in the chorionic plate becomes more prominent giving the appearance of cotyledons. There is also appearance of hemorrhagic infarcts and calcifications. The fetus grow in utero and become macrosomic which may lead to cephalopelvic disproportion, prolonged labor or shoulder dystocia. $^{16}$

Mothers are at risk of labor dystocia, severe perineal lacerations, operative vaginal delivery, caesarean deliveries. Risk of complications such as chorioamnionitis, severe perineal lacerations, endomyometritis all increase progressively. The emotional impact of prolonged pregnancy should not be underestimated either.

Postdated pregnancy is an obstetric situation which demands special attention in developing countries where neglected pregnancies are common. Accurate assessment of gestational age and diagnosis of postdated pregnancy as well as recognition and management of risk factors may reduce the risk of adverse outcomes. ${ }^{17}$ Though the correct choice of management remains controversial, considering the above mentioned complications most of the patients will benefit from more aggressive induction of labor at 41 weeks. ${ }^{18}$ With this background the present study was undertaken to find out the maternal and fetal outcome was in pregnancy beyond 40 weeks of gestation to know the maternal complications beyond expected date of delivery and to know fetal morbidity and mortality.

Objectives of the study was to study the maternal complications in postdated pregnancies and to study the neonatal outcome in postdated pregnancies.

\section{METHODS}

This cross sectional observational study was carried out in the Department of Obstetrics and Gynecology in R.L. Jalappa hospital which is a tertiary care centre from July 2018 to July 2019. Data will be collected from previous records of postdated pregnancies of RLJH hospital during the period of study. Approval of the institutional ethics committee was taken prior to commencement of the study.

Sample size for the study is estimated based on the major complications associated with postdated pregnancies i.e., meconium aspiration syndrome that was reported to be $13 \%$ in a study called "Management and outcome of post-dated pregnancy at Rajshahi Medical College and Hospital." The estimated sample size with 99\% confidence interval and 5\% absolute error is 106. 


\section{Inclusion criteria}

Pregnant women more than 40 weeks of gestation, who were sure about LMP and their pregnancy was dated by 1st trimester scan, singleton pregnancies, cephalic presentation were included in the study.

\section{Exclusion criteria}

Women who were not sure about LMP, not dated by early scan, multiple pregnancy, pregnancies complicated by medical disorders, fetal anomalies were excluded from the study.

Data was collected using case record form after taking informed consent of the participants during the study period. Total 106 patients were selected based on the gestational age of the patients. Detailed clinical history was noted including menstrual, obstetrics history, past, personal and family history. Gestational age was calculated as per the LMP and the first trimester scan. If there was a discrepancy of more than 5 days, the gestational age as per the first trimester was considered. The patients general condition, systemic examination and per abdominal examination were recorded. Records were kept about the mode of delivery and if any postpartum maternal complication if occurred. The baby details were noted. The cause of NICU admission was noted if there were any. Any neonatal deaths that occurred were also recorded. Data collected was entered in Microsoft Excel Spread Sheet Using statistical package for social services (SPSS) for analysis.

\section{RESULTS}

Table 1: Distribution of participants according to their demographic data.

\begin{tabular}{|c|c|c|c|}
\hline $\begin{array}{l}\text { Demographic } \\
\text { data }\end{array}$ & & $\begin{array}{l}\text { No. of } \\
\text { participants }\end{array}$ & $\begin{array}{l}\text { Percent } \\
(\%)\end{array}$ \\
\hline \multirow{5}{*}{$\begin{array}{l}\text { Age group } \\
\text { (in years) }\end{array}$} & $18-21$ & 27 & 25 \\
\hline & $21-24$ & 40 & 37 \\
\hline & $24-27$ & 22 & 20 \\
\hline & $27-30$ & 11 & 10.3 \\
\hline & $30-33$ & 6 & 5 \\
\hline \multirow[b]{2}{*}{$\begin{array}{l}\text { Gestational } \\
\text { age }\end{array}$} & $\begin{array}{l}40 \text { weeks }-40 \\
\text { weeks } 6 \text { days }\end{array}$ & 85 & 79.4 \\
\hline & $\begin{array}{l}41 \text { weeks - } \\
41 \text { weeks } 6 \\
\text { days }\end{array}$ & 21 & 19.8 \\
\hline \multirow{2}{*}{ Parity } & Primigravida & 58 & 55 \\
\hline & Multigravida & 48 & 45 \\
\hline \multirow{2}{*}{$\begin{array}{l}\text { Booking } \\
\text { status }\end{array}$} & Booked & 47 & 44 \\
\hline & Unbooked & 59 & 56 \\
\hline
\end{tabular}

Out of 106 patients who were studied majority i.e., 59 patients $(56 \%)$ were unregistered with our health care centre where as 47 patients $(44 \%)$ were registered with us for regular ANC visits. Mean age of the patients that were studied was 22. Maximum participants were in the age group 21-24 years. The least number of participants were above 30 years of age (Table 1).

Table 2: Distribution of participants based on their clinical parameter.

\begin{tabular}{|c|c|c|c|}
\hline $\begin{array}{l}\text { Clinical } \\
\text { parameter }\end{array}$ & & $\begin{array}{l}\text { Number of } \\
\text { participants }\end{array}$ & Percentage \\
\hline \multirow{3}{*}{$\begin{array}{l}\text { Mode of } \\
\text { delivery }\end{array}$} & FTND & 50 & 47 \\
\hline & $\begin{array}{l}\text { Cesarean } \\
\text { section }\end{array}$ & 48 & 45 \\
\hline & $\begin{array}{l}\text { Operative } \\
\text { vaginal } \\
\text { delivery }\end{array}$ & 6 & 5 \\
\hline \multirow{2}{*}{ FTND } & Spontaneous & 9 & 18 \\
\hline & Induced & 41 & 82 \\
\hline \multirow{2}{*}{$\begin{array}{l}\text { Operative } \\
\text { vaginal } \\
\text { delivery }\end{array}$} & $\begin{array}{l}\text { Forceps } \\
\text { assisted }\end{array}$ & 2 & 25 \\
\hline & $\begin{array}{l}\text { Vacuum } \\
\text { delivery }\end{array}$ & 4 & 75 \\
\hline
\end{tabular}

Table 3: Distribution of participants based on indication for $\mathrm{C}$ section.

\begin{tabular}{|lll|}
\hline $\begin{array}{l}\text { Cesarean delivery } \\
\text { indications }\end{array}$ & $\begin{array}{l}\text { Number of } \\
\text { participant }\end{array}$ & Percentage \\
\hline Meconium stained liquor & 12 & 25 \\
\hline Severe oligohydramnios & 10 & 21 \\
\hline Fetal distress & 8 & 17 \\
\hline CPD & 6 & 13 \\
\hline Previous LSCS & 5 & 10 \\
\hline Non progression & 3 & 6 \\
\hline Failed induction & 2 & 4 \\
\hline Obstructed labour & 2 & 4 \\
\hline
\end{tabular}

Table 4: Distribution of participants based on the fetal outcome.

\begin{tabular}{|lll|}
\hline Fetal outcome & $\begin{array}{l}\text { Number of } \\
\text { participants }\end{array}$ & Percentage \\
\hline Motherside & 61 & 58 \\
\hline NICU admission & 45 & 42 \\
\hline
\end{tabular}

Table 5: Distribution of participants based on cause for NICU admission of the baby.

\begin{tabular}{|lll|}
\hline $\begin{array}{l}\text { Cause of NICU } \\
\text { admission }\end{array}$ & $\begin{array}{l}\text { Number of } \\
\text { participants }\end{array}$ & Percentage \\
\hline Fetal distress & 21 & 20 \\
\hline $\begin{array}{l}\text { Thick meconium } \\
\text { stained liquor }\end{array}$ & 12 & 11 \\
\hline Macrosomia & 2 & 2 \\
\hline Perinatal asphyxia & 6 & 6 \\
\hline IUGR & 4 & 4 \\
\hline
\end{tabular}

Table 6: Distribution of participants based on maternal complications. 


\begin{tabular}{|c|c|c|}
\hline Maternal complications & $\begin{array}{l}\text { Number of } \\
\text { participants }\end{array}$ & Percentage \\
\hline Post partum haemorrhag & 7 & 54 \\
\hline Septicemia & 1 & 8 \\
\hline Perineal tears & 3 & 23 \\
\hline Obstructed Labour & 2 & 15 \\
\hline
\end{tabular}

Majority of patients i.e 85 patients (80.1\%) had gestational age between 40 weeks to 40 weeks 6 days and 21 patients $(19.8 \%)$ had gestational age between 41 weeks to 41 weeks 6 days. Majority of the patients belonged to the primigravida group $58(55 \%)$ and $48(45 \%)$ patients were multigravida (Table 1). 14 out of 48 multigravidas had history of previous postdated pregnancies. Out of 50 patients who had full term normal delivery 41 (82\%) were induced and delivered vaginally and 9 patients (18\%) had spontaneous onset of labor (Table 2). Mode of delivery in 61 patients $(58 \%)$ was found to be Full term normal delivery and 48 patients (49\%) underwent cesarean section and 3 patients had operative vaginal delivery (Table 2).

Among all the patients who needed operative vaginal delivery (8), majority of 6 cases $(75 \%)$ was delivered by Vacuum assisted vaginal delivery and 2 patients $(25 \%)$ had forceps delivery (Table 2). Among all the patients who underwent cesarean section (48), indication for caesarean section was thick meconium stained liquor with poor bishop score in 12 patients (25\%). Severe oligohydramnios was indication in 10 cases $(21 \%)$ which was followed by isolated fetal distress in 8 cases $(17 \%)$ and CPD in 6 cases (13\%). 5 cases $(10 \%)$ underwent cesarean section in view of previous LSCS and 3 cases ( $6 \%$ ) due to non-progression of labor, 2 patients also underwent section due to failed induction and another 2 due to obstructed labor (Table 3).

The majority $61(58 \%)$ babies born to participants did not need NICU admission, while 45 babies (42\%) were admitted to NICU (Table 4). The primary reason as to their admission to NICU was fetal distress, seen in 21 babies $(20 \%)$ and thick meconium stained liquor in 12 babies $(11 \%)$ followed by perinatal asphyxia in 6 babies $(6 \%) .4$ babies $(6 \%)$ were IUGR because of which they got admitted to NICU and 2 babies because of macrosomia (4\%) (Table 5). No neonatal deaths were recorded. Out of the total patients studied, 13 patients ended up with some complications. In this study 7 patients $(54 \%)$ had post-partum hemorrhage, 3 patients had perineal tears, 2 patients went into obstructed labor and 1 patient (15\%) had septicemia (Table 6).

\section{DISCUSSION}

The aim of the study was to evaluate the maternal and fetal complications associated with postdated pregnancies. This study includes both primigravida and multigravida admitted between July 2018 to July 2019 in the department of Obstetrics and Gynecology in Sir Devraj Urs Medical College, Kolar.

In our study out of 100 cases, 40 cases were between 21 24 years, 22 between $24-27$ years and 6 cases $(5 \%)$ were above 30 years. The mean age in our study was 22 years, while the mean age in Mahapatro's study was 24.19 and Eden et al.' s study was 25.8 years. ${ }^{19,20}$ In our study majority of the cases were primigravida $(58 \%)$ which is similar to Mahapatro and Alexander et al.'s study. ${ }^{19,21}$ In our study out of 100 cases 50 were full term normal deliveries, whereas 44 cases were of LSCS and 6 cases were of instrumental deliveries. It was observed that out of the 50 cases who delivered normally only 9 cases (18\%) delivered spontaneously and 41 cases (82\%) delivered after induction of labor. In our study the rate of LSCS was $45 \%$ whereas in Singhal et al it was $16.7 \%$ and in the study of Mahapatro it was $28.9 \% .^{19,22}$

The rate of instrumental delivery was $5 \%$ in our study which is similar to the study done by Mahapatro where it was $5.72 \% .{ }^{19}$ In the study done by Singhal et al it was $8.6 \%$. In our study it was observed that Meconium stained liquor with fetal distress was the most common indication of LSCS (46\%), like in Mahapatro's study where fetal distress was the most common indication $(65.5 \%) .{ }^{19}$ Total NICU admissions in our study was seen in $42 \%$ of the cases, most common indication for which was fetal distress $(21 \%)$. Most common maternal complication that occurred was postpartum hemorrhage seen in 7 cases.

\section{CONCLUSION}

Management of postdated pregnancy is a challenge to obstetrician and a careful advice and monitoring can alleviate maternal anxiety and untoward complications. Frequent Amniotic fluid index monitoring should be done in pregnancy beyond 40 weeks as in our study we found more cases of oligohydramnios. In our study we concluded that prolonged pregnancy was associated with significant risk of perinatal complications such as fetal distress, meconium aspiration syndrome and IUGR. There was increased risk of obstetric complications as well like atonic PPH, oligohydramnios, obstructed labor. The adverse outcome can be reduced by making accurate gestational age and diagnosis of postdated pregnancies as well as recognition and management of risk factors.

Funding: No funding sources

Conflict of interest: None declared

Ethical approval: The study was approved by the Institutional Ethics Committee

\section{REFERENCES}

1. Chabra, Shilpi MD. Post term, postdates and prolonged pregnancy. Obst Gynecol. 2015;125(4):980-1. 
2. Galal M, Symonds I. Post term pregnancy: facts views and vision. Obst Gynecol. 2012;4(3):175-87.

3. Schoen C, Campbell S, Maratas A, Kim C. Anaphylaxis to buccal misoprostol for labor induction. Obstet Gynaecol. 2014;124(I):466-8.

4. Bhriegu R, Agarwal M, Hariharan C. Assessment of maternal and perinatal outcome in postdated pregnancies. Journal DMIMSDU. 2017;12(1):35-40.

5. Neilson JP. Ultrasound for fetal assessment in early pregnancy. Cochrane Database Syst Rev. 2000;(2:CD000182).

6. Crowley P. The Cochrane Library. Chicester, UK: John Wiley \& Sons, Ltd; 2004. Interventions for preventing or improving the outcome of delivery at or beyond term (Cochrane review).

7. Mogren I, Stenlund H, Hogberg U. Recurrence of prolonged pregnancy. Int J Epidemiol. 1999;28:2537.

8. Divon MY, Ferber A, Nisell H. Male gender predisposes to prolongation of pregnancy. Am J Obstet Gynecol. 2002;187:1081-3.

9. Kiran TS, Hemmadi S, Bethel J. Outcome of pregnancy in a woman with an increased body mass index. BJOG. 2005;112:768-72.

10. Laursen M, Bille C, Olesen AW. Genetic influence on prolonged gestation: a population-based Danish twin study. Am J Obstet Gynecol. 2004;190:489-94.

11. Jones JP, Fox H. Ultrastructure of placenta in prolonged pregnancy. J Pathol. 1978;126(3):173-9.

12. Hilder L, Costeloe K, Thilaganathan B. Prolonged pregnancy: evaluating gestation-specific risks of fetal and infant mortality. $\mathrm{Br} \mathrm{J}$ Obstet Gynaecol. 1998;105:169-73.

13. Hannah ME. Postterm pregnancy: should all women have labour induced? a review of the literature. Fetal Matern Med Rev. 1993;5:3.
14. Berkowitz K, Garite T, Global Library of Women's Medicine. 2008:1756-2228.

15. Alexander JM. Forty weeks and beyond: pregnancy outcomes by week of gestation. Obst Gynecol. 2017;96(2):291-4.

16. Vorherr H. Placental insufficiency in relation to post term pregnancy and fetal post maturity: Evaluation of fetoplacental function; management of the post term gravida. Am J Obst Gynecol. 1975;123(1):67103.

17. Kumari R, Singh M. Observational study on mode of delivery in pregnancy beyond expected date of delivery at rims Ranchi. IOSR J Dental Med. 2018;17(8):61-4.

18. Kandalgaonkar VK, Kose V. Fetomaternal Outcome in postdated pregnancy. 2019;8(5):1899-906.

19. Mahapatro A. Fetomaternal outcome in pregnancy beyond 40 weeks. Int J Pharm Bio Sci. 2015;6:53-8.

20. Eden RD, Gergely RZ, Schifrin BS, Wade ME. Comparison of antepartum testing schemes for the management of the postdate pregnancy. Am J Obstet Gynecol. 1982;144:683-92.

21. Alexander JM, McIntire DD, Leveno KJ. Forty weeks and beyond: pregnancy outcomes by week of gestation. Obstet Gynecol. 2000;96:291-4.

22. Singhal P. Fetomaternal outcome following postdate pregnancy. a prospective study. J Obstet Gynecol India. 2001;51:89-93.

Cite this article as: Narayan R, Sheela SR. A cross sectional observational study to evaluate the maternal and fetal outcome in postdated pregnancies. Int $\mathbf{J}$ Reprod Contracept Obstet Gynecol 2021;10:159-63. 